\title{
CONHECENDO A CIDADE, DESCOBRINDO O OLHAR: UMA EXPERIÊNCIA DE EDUCAÇÃO PATRIMONIAL COM HISTÓRIA E FOTOGRAFIA
}

\author{
KNOWING THE CITY, DISCOVERING THE LOOK: AN EXPERIENCE OF \\ EDUCATION SHEET WITH HISTORY AND PHOTOGRAPHY
}

Maria das Graças de Andrade Leal ${ }^{1}$

\begin{abstract}
RESUMO: Refere-se a um projeto de pesquisa-ação iniciado em 1998, no contexto do Programa Educacional do Liceu. Destinado aos jovens de 14 a 17 anos, teve o objetivo de promover a construção de conhecimentos sobre a história da cidade do Salvador, considerada referencial de identidades, na perspectiva da valorização da vida e de todo o patrimônio que a cerca, como princípio de fortalecimento da participação cidadã nas dimensões individual e coletiva, local e global. Teve como preocupação inicial refletir sobre problemáticas presentes na cidade do Salvador, especialmente nas regiões históricas e em particular no Centro Histórico de Salvador, considerado patrimônio da humanidade, referentes às concepções e fragilidades de políticas públicas sobre a preservação e proteção do patrimônio histórico, artístico, cultural e natural na Bahia. Para isso justapõe o trabalho do historiador e do fotografo.
\end{abstract}

Palavras-chave: Educação Patrimonial. Cidade. Fotografia.

\begin{abstract}
Refers to an action research project started in 1998 in the context of the School Education Program. For young people 14-17 years, aimed to promote the construction of knowledge about the history of the city of Salvador, considered referential identity, in the perspective and appreciation of life and all the heritage that surrounds it, as a principle of strengthening citizen participation in the individual and collective, local and global. Initial concern was to reflect on these issues in the city of Salvador, especially in historical regions and particularly in the historic center of Salvador, considered patrimony of humanity, referring to the concepts and weaknesses of public policies on the preservation and protection of historical, artistic, cultural and natural in Bahia. For that juxtaposes the work of the historian and photographer.
\end{abstract}

Keywords: Heritage Education. City. Photography.

\footnotetext{
1 Universidade do Estado da Bahia (UNEB)/Departamento de Educação-Colegiado de História/Campus II e Mestrado em História Regional e Local/Campus V.
} 


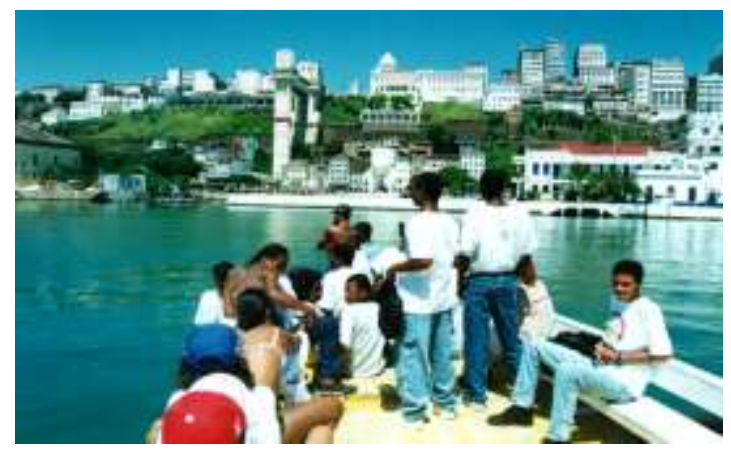

Foto 1 - Jovens na Baía de Todos os Santos. Foto Isabel Gouvêa, 1998

Conhecendo a Cidade, Descobrindo o Olhar está me ajudando a olhar as coisas de um jeito diferente.

Belas paisagens foram registradas pelas fotos e pela memória, que é a nossa principal máquina fotográfica.

Valquíria Rangel (16 anos)

\section{Introdução}

Este artigo relata e analisa uma experiência educacional realizada no Liceu de Artes e Ofícios da Bahia ${ }^{2}$, cuja metodologia foi construída por profissionais de história e fotografia ${ }^{3}$, fundamentada no conceito de Educação Patrimonial. Foi um projeto de pesquisa-ação iniciado em 1998, no contexto de aprimoramento das práticas educativas do Programa Educacional do Liceu em seu compromisso com a cultura e a cidadania. Destinado aos jovens de 14 a 17 anos, teve o objetivo de promover a construção de conhecimentos sobre a história da cidade do Salvador, considerada referencial de identidades, na perspectiva da valorização da vida e de todo o patrimônio que a cerca, como princípio de fortalecimento da participação cidadã nas dimensões individual e coletiva, local e global. A cidade foi ponto de partida e de chegada de experiências, emoções, fazeres

2 Instituição educacional fundada em 1872 e revitalizada em 1988, após um incêndio ocorrido em 1968, com o objetivo de desenvolver a formação de jovens em situação de vulnerabilidade social para a vida pelo trabalho. A instituição foi desativada no ano de 2008.

3 Participaram da idealização, pesquisa, elaboração, execução da experiência Conhecendo a Cidade, Descobrindo o Olhar, de 1998 a 2000, a historiadora Maria das Graças de Andrade Leal e a fotógrafa Isabel Gouvêa. 
e saberes que envolveram elaborações, percepções, sensibilidades expressadas pelo olhar curioso e estético dos jovens pela fotografia. 0 laboratório vivo, a sala de aula aberta, o espaço de trocas de conhecimentos foram a Salvador antiga e região metropolitana, carregadas de história, mitos e interrogações em sua convivência com a modernidade.

De projeto a exercício de práticas pedagógicas foram diversos caminhos traçados para validarmos alguns princípios educacionais, políticos, sociais, culturais baseados na participação ativa, atuante, reflexiva e crítica de todos os envolvidos, especialmente dos jovens produtores de conhecimento. ${ }^{4}$ Teve como preocupação inicial refletir sobre problemáticas presentes na cidade do Salvador, especialmente nas regiões históricas e em particular no Centro Histórico de Salvador, considerado patrimônio da humanidade, referentes às concepções e fragilidades de políticas públicas sobre a preservação e proteção do patrimônio histórico, artístico, cultural e natural na Bahia. Vinculou-se, de um lado, a aspectos relativos à crise da memória, enquanto prática e representação, e, paradoxalmente, sua coexistência, por outro, com a efervescência da memória, considerada na ordem do dia como suporte dos processos de identidade e reivindicações respectivas, a exemplo da "busca pela divulgação da autoimagem: Estado (organismos documentais e de proteção do patrimônio cultural); entidades privadas; empresas; imprensa; partidos políticos; movimentos sindicais, de minorias e marginalizados; associações de bairro, organizações da sociedade civil, etc." ${ }^{5}$

\footnotetext{
${ }^{4}$ Entre os diversos estudos que discutem métodos para educação popular ver: FEIRE, P. Pedagogia do Oprimido. 4 ed. São Paulo: Paz e Terra, 1977; COLL, C. Aprendizagem Escolar e Construção do Conhecimento. Porto Alegre: Artes Médicas, 1994; SAVIANI, D. Pedagogia histórico-crítica: primeiras aproximações. Campinas, São Paulo: Editora Autores Associados, 1995.

${ }^{5}$ Sobre as problemáticas da memória nas dimensões epistemológicas, técnicas, existenciais e socioeconômicas ver análise de MENESES, U. T. B. A crise da Memória, história e documento in SILVA, Z. L. da (org.). Arquivos, patrimônio e memória: trajetórias e perspectivas. São Paulo: UNESP; FAPESP, 1999, pp. 11-29.
} 


\section{Sobre a Questão do "Resgate" do Patrimônio Cultural}

Muito se tem discutido em torno de palavras-chave como "resgate", "recuperação", "preservação", "revitalização", "proteção" do patrimônio, as quais apontam para alguns pressupostos, como se refere Meneses (1999), tais como fragilidade, perda de substância, associadas à indústria e reificação do patrimônio cultural ligadas, por seu turno, à comunicação de massa e ao mercado, especialmente em se tratando de interesses vinculados à indústria do turismo. Enquanto, na Bahia, o turismo torna-se importante meio de crescimento da economia, beneficiando, especialmente, grandes empresários do mercado turístico, nacionais e internacionais, a população baiana sente o reflexo inverso relacionado à sua inserção, não somente produtiva no setor, mas, principalmente, à sua inserção cidadã sobre o ambiente cultural explorado economicamente, mas não associado ao povo que representa não somente aquele que recebe visitantes no cotidiano dos lugares, mas aquele que vive sem conhecer profundamente e valorizar os lugares onde habita. Primeiro considerar a população local como principal beneficiário das conquistas econômicas, culturais, artísticas, históricas, para se promover um turismo cidadão, com a participação dos habitantes incluídos naquilo que representa a dinâmica produtiva, de oportunidades de trabalho e renda, mas, acima de tudo, promover o significado cidadão de tal participação como direito à memória, a todos os espaços históricos, culturais, artísticos, etc.

Diante de tais problemáticas, partimos para a aplicação de uma proposta educacional que vislumbrasse discutir com jovens de baixa renda, residentes em bairros periféricos de Salvador, com dificuldades de acesso a uma escola de qualidade e de inserção no mercado de trabalho, aspectos relacionados ao patrimônio histórico, artístico, cultural, natural da cidade onde eles habitam e onde constroem o seu próprio patrimônio. Desta forma, foram adotados, com referência ao entendimento sobre educação patrimonial, alguns conceitos correlatos, nos quais estão presentes a memória individual e coletiva, cultura, patrimônio e educação.

Partimos do pressuposto de que todo ser humano deseja a imortalidade e que, para tanto, por saber-se finito, cria, no seu processo 
cultural de existência, no seu fazer cotidiano, nas suas elaborações e reelaborações sobre o mundo, estratégias de perpetuação. Voluntária ou involuntariamente, a humanidade documenta a sua passagem pelo mundo, criando objetos, monumentos, símbolos, produzindo textos, arte, inventando, interpretando, registrando a sua presença, a sua existência. Para Carneiro, este é o objetivo do ser humano - ser lembrado. E pela lembrança, sobrevive. (CARNEIRO, 2008).

E assim, a humanidade deixa de herança uma memória que será "lida" pelas gerações futuras, interpretadas e inventadas conforme visões de mundo, ideologias, métodos, narrativas. Neste sentido, o estudo da memória, para Le Goff, não é exclusividade da história, mas também da antropologia, da psicologia e da educação, apesar de ganhar uma significação particular na história onde "o estudo da memória social é um dos meios fundamentais de abordar os problemas do tempo e da história." (LE GOFF, 1996, p. 426)

Para Chaui, a memória possui duas dimensões: a pessoal, introspectiva, cuja recordação é individualizada; a coletiva e social, transformada em memória objetiva, gravada nos monumentos, documentos e relatos da história de uma sociedade. (CHAUI, 2005, p. 138) Portanto, é no coletivo, no social, que o monumento, os documentos na sua expressão mais larga, se configuram em patrimônio de um povo, conforme Mariuzzo:

Monumentos são parte do patrimônio cultural de um povo ou de uma nação, eles servem como um elo entre presente e passado dando um sentido de continuidade. A preservação do patrimônio pressupõe um projeto de construção do presente, e por isso vale a pena na medida em que este patrimônio esteja vivo no presente, vivo para que as pessoas que o cercam possam de algum modo usufruir dele. (MARIUZZO, 2004)

Le Goff, ao refletir sobre a relação entre documento e monumento, conclui que a memória, ao ganhar um caráter de monumento, deve ser visitada pelo historiador partindo do princípio de que "todo documento tem em si um caráter de monumento e não existe memória coletiva bruta" (LE GOFF, 1996, p. 433), pois ela é sempre lapidada pelo contingenciamento da

\footnotetext{
${ }^{6}$ http://www.labjor.unicamp.br/patrimonio/materia.php?id=139 (acesso 16 de mar;o de 2011)
} 
lembrança, distância temporal e social, entre outras distâncias. Assim, o monumento tem o sentido de fazer recordar, instruir, emitir sinais do passado. Ou seja, evoca o passado para perpetuar a recordação, liga-se ao poder de perpetuação, voluntária ou involuntária, como legado à memória coletiva. Como estímulo da memória para a recordação, o monumento ou os diferentes documentos e todos os bens culturais de comunidades representam para pessoas ou para uma sociedade elos significativos de continuidade entre o que foi e o que é, ganhando, assim, status de Patrimônio. Sendo assim, o que pode merecer significado social ao patrimônio seria, justamente, o interesse pelo presente e, portanto, como meio de ligação com o passado, deve fazer sentido no nosso cotidiano.

Embutidas no conceito de patrimônio estão presentes dimensões amplificadas no que entendemos por cultura. assim, todas as formas de representação, todos os fazeres e saberes de um povo em seu conjunto é cultura $^{7}$ e, portanto, são objetos de valorização patrimonial que devem estar integrados aos objetivos educacionais, preservacionistas, conservacionistas. não apenas obras arquitetônicas monumentais, de apelo evocativo e comemorativo aos grandes feitos do passado, antiguidades, de valor estético, mas aquilo que tem significado para uma sociedade, o que "contribui para a construção de sua identidade cultural e o exercício da cidadania." (oriá, 2001, p. 138)

Considerando a própria história dos órgãos públicos responsáveis pela proteção do patrimônio cultural no Brasil, desde a década de 1920 até à criação, em 1937, do então denominado Serviço do Patrimônio Histórico e Artístico Nacional (SPHAN), responsável pela identificação, documentação, fiscalização, preservação e promoção do patrimônio cultural brasileiro, atual Instituto do Patrimônio Histórico e Artístico Nacional (IPHAN), diversos entendimentos sobre critérios para eleição de bens artísticos, históricos, arquitetônicos a serem preservados passaram por transformações políticas e conceituais. O que antes era considerado apenas objeto de proteção o

\footnotetext{
7 Sobre a nova história cultural, tomamos por base autores como BURKE, Peter (org.). $A$ escrita da história: novas perspectivas. São Paulo: UNESP, 1992; CHARTIER, Roger. A história cultural: entre práticas e representações. Lisboa: Difel /Rio de Janeiro: Bertrand Brasil, 1990; HUNT, Lynn. A nova história cultural. São Paulo: Martins Fontes, 1992.
} 
patrimônio material (ou bens tangíveis), ou seja, aquele que integra edifícios, obras de arte, sítios arqueológicos, conjunto arquitetônico de cidades, com o Decreto 3.551/2000, que regulamentou o artigo 216 de Constituição de 1988, foi criado o Programa Nacional do Patrimônio Imaterial (PNPI) e instituiu, como formas de proteção, o registro em livros temáticos no IPHAN e inventário. Houve o alargamento da concepção de patrimônio cultural. O Patrimônio cultural imaterial (ou patrimônio cultural intangível) é uma concepção de patrimônio abrange expressões culturais e tradições preservadas por grupos de indivíduos, em respeito da sua ancestralidade, para as gerações futuras, tais como os saberes, os modos de fazer, as formas de expressão, celebrações, as festas e danças populares, lendas, músicas, costumes e outras tradições. ${ }^{8}$

Diante da pluralidade presente na concepção de patrimônio em suas dimensões políticas, sociais, culturais, econômicas, naturais, a educação patrimonial passa a integrar uma área a ser explorada no universo do conhecimento e das políticas públicas de proteção à vida em seu sentido sócio-ambiental. Especialmente em se tratando de um país como o Brasil, ainda carente de ações mais enfáticas de proteção do nosso patrimônio cultural, social e natural, e particularmente na Bahia, cujas ações se constituem ainda tímidas para a problemática presente nas cidades incluídas no circuito de visitações, pesquisas, estudos acadêmicos sobre história, cultura, economia, meio ambiente, turismo.

Para Fernandes (1992/1993), os lugares e suportes da memória, como museus, monumentos históricos, arquivos, bibliotecas, sítios históricos, vestígios arqueológicos, são os espaços privilegiados no processo educativo para se "desenvolver a sensibilidade e a consciência dos educandos e dos cidadãos para a importância da preservação desses bens culturais." Neste sentido, segundo o mesmo historiador, a educação patrimonial, como proposta interdisciplinar de ensino voltada para questões atinentes ao patrimônio cultural,

\footnotetext{
8 Sobre legislação e processos de tombamento ver: http://www.cultura.gov.br/site/categoria/politicas/patrimonio-e-monumenta/patrimoniomaterial/ também http://www.brasil.gov.br/sobre/cultura/patrimonio/patrimonio-materiale-imaterial e http://pt.wikipedia.org/wiki/Patrim\%C3\%B4nio_cultural_imaterial
} 
Compreende desde a inclusão, nos currículos escolares de todos os níveis de ensino, de temáticas ou de conteúdos programáticos que versem sobre $o$ conhecimento $e$ a conservação do patrimônio histórico, até a realização de cursos de aperfeiçoamento e extensão para os educadores e a comunidade em geral, a fim de Ihes propiciar informações acerca do acervo cultural, de forma a habilitá-los a despertar, nos educandos e na sociedade, o senso de preservação da memória histórica e o conseqüente interesse pelo tema. (FERNANDES, 1992/1993, p. 273-274)

No Projeto Conhecendo a Cidade, Descobrindo o Olhar, educação patrimonial é considerada ainda como proposta interdisciplinar de ensino e "instrumento de alfabetização cultural", por possibilitar ao indivíduo leituras de mundo e a "compreensão do universo sociocultural e da trajetória histórico-temporal em que está inserido". (GUIMARÃES, 2009, p. 6) Contudo, o objeto de conhecimento foi estendido para além do patrimônio cultural acima referenciado, ao incluirmos, na dinâmica do conhecimento proposto, as subjetividades dos jovens participantes associadas ao autoconhecimento, ao fortalecimento da autoestima, à busca de motivações intrínsecas em cada história de vida, a fim de promover o olhar indagador e estético sobre a vida e de toda a produção cultural, social e a existência natural que rodeia cada indivíduo no complexo da coletividade.

Entendemos, desta forma, que a educação, como processo contínuo e compartilhado, vinculada à dimensão patrimonial, faz parte das conquistas de cidadania a serem fortalecidas nos diversos setores da vida, especialmente em se tratando do nosso tempo de modernidade, de individualismos exacerbados, das novas tecnologias, no contexto de existências de pessoas como os jovens participantes do Projeto, em todas as suas fragilidades, forças e potencialidades. A conquista maior a ser encarada está na proteção, preservação e transformação do patrimônio individual e coletivo sintetizado na cidadania ambiental, o que significa conquistas políticas, sociais, culturais, econômicas de inclusão ampla e irrestrita.

Conforme Ana Carmen Casco, a educação deverá, neste sentido, assumir 
Seu papel de agente no processo social, produtora de saber e não apenas consumidora e reprodutora de conhecimentos dados; as ações educativas voltadas para a preservação devem contribuir para a formação de sujeitos ativos e livres na construção de sua própria vida e da dimensão coletiva a ela inerente. É essa dimensão coletiva, conquistada e reafirmada, que permite ao indivíduo resignificar termos como cidadania, participação, responsabilidade e pertencimento. A educação pode ser um dos meios através dos quais se desvende o rosto digno da diversidade brasileira. (CASCO, 2006)

Assim, com os propósitos de estimular o interesse e provocar formas de conhecimento em torno da história da cidade do Salvador e do seu cotidiano, motivando os jovens a construírem subjetiva e objetivamente atitudes e competências para atuarem como cidadãos reflexivos, críticos e comprometidos com o ambiente em que vivem, a fotografia se constituiu em meio para a ampliação da percepção estética e criativa sobre os lugares, as paisagens sociais, arquitetônicas, naturais, culturais exploradas. Para tanto, diversas ações educativas e integradoras privilegiaram temas vinculados à realidade sóciocultural brasileira, caracterizada pela dinâmica da pluralidade, nas suas elaborações e reelaborações. Recortamos os "Brasis" e privilegiamos a Bahia como objeto direto de conhecimento, por ter sido a primeira edição do Brasil, onde foi implantada a sua primeira capital e ainda por ser ponto de convergência de culturas européias, africanas e americanas, onde diversos povos construíram uma história plural, rica por integrar uma diversidade étnica e racial que hoje pode ser identificada por aqueles que estão presentes no dia-a-dia urbano e rural através dos afrodescendentes, indígenas, sertanejos, imigrantes de todos os lugares.

A utilização da linguagem fotográfica se constituiu em recurso pedagógico privilegiado para o desenvolvimento do raciocínio concreto, da observação, reflexão e capacidade estética e criativa dos jovens. A prática da observação e percepção foi realizada através de visitas orientadas a pontos históricos de Salvador e entorno, nos quais os jovens produziram fotos com câmeras amadoras de 35mm, registrando conteúdo, estética, criatividade e documentando o tangível e intangível presentes na sociedade baiana. 
Para tanto, vislumbramos neste projeto uma possibilidade pedagógica de apropriação cidadã por parte de jovens em situação de desvantagem social do espaço em que habitam, construindo relações de identidade entre o conhecido e o vivido, reelaborando valores e atitudes relacionados aos princípios de valorização, preservação da vida na sua complexidade e simplicidade, na sua luz e sombra, na sua eternidade e transitoriedade, de forma crítica e criativa. Vida como patrimônio a ser protegido no que há na natureza e no que há de produzido pelos homens em sua historicidade.

Ao refletir sobre o papel da educação e da preservação do patrimônio e da memória, inscritas nos diferentes territórios do político, econômico e social, Ana Carmen Casco assinala de forma primorosa serem as dimensões das ações educativas e de preservação constituídas por interesses afetivos e "amorosos que são, por sua vez, transformadores."

\begin{abstract}
Ensinar o respeito ao passado, mais do que a sua simples valorização, é contribuir para a formação de uma sociedade mais sensível e apta a construir um futuro menos predatório e descartável, menos submetido à lógica econômica de um mercado cada vez mais voltado para os jovens, seus hábitos e seus gostos (ou a falta e a volatilidade destes). É construir uma sociedade que respeite seus velhos como portadores de saberes e tradições que precisam e devem ser reinventados ou transmitidos, em sua integridade, às gerações futuras. Uma sociedade culta é uma sociedade cultivada, seja pelos meios formais de educação - a escola -, seja pelos informais - a família, os mestres, as práticas sociais etc. E será culta, no sentido mais amplo de portadora de uma cultura, na medida em que for capaz de escolher, no passado e no presente, aqueles - objetos, signos, pessoas, tradições etc. - com os quais quer construir sua linha do tempo no mundo. (CASCO, 2006, p. 3)
\end{abstract}

A articulação da história com a fotografia objetivou ampliar as possibilidades de se produzir conhecimentos históricos, artísticos, técnicos, culturais, de forma envolvente e prazerosa, que implicasse diretamente os jovens no processo de produção de conhecimentos relacionados à cidade do Salvador e à vida de cada um na cidade. Promoveu, dessa forma, a aproximação dos jovens à sua realidade urbana, estabelecendo um diálogo permanente com a sua história, a sua cidade, o seu patrimônio artísticocultural e ambiente natural, ou seja, com a sua identidade. 


\section{Conteúdos e Metodologia}

Através da metodologia sócio-interacionista, atividades teóricas e práticas foram aplicadas em formato de oficinas dinâmicas e participativas, com grupos de 25 jovens, nas quais eram articulados conhecimentos específicos de história e fotografia permeados por temas de conteúdo político, social, artístico, cultural e ambiental. Conhecer a história da cidade a partir da história de vida de cada jovem, foi um ponto de partida para a motivação inicial dos processos subsequentes de construção dos conhecimentos. O foco foi o jovem em um movimento de regaste da sua auto-estima, de reconhecimento da sua condição de sujeito de transformação e preservação na dinâmica do tempo. Compreendeu-se ser uma abordagem importante para que dominassem conhecimentos inerentes a si mesmos, enquanto habitantes de uma cidade rica em diversidade étnica e cultural, plural em sua identidade. Teve o objetivo de proporcionar pleno acesso aos recursos culturais relevantes, para que todos pudessem criar condições complementares para o seu crescimento enquanto cidadãos participativos e engajados nas causas da preservação do patrimônio social, cultural, humano, natural e ao mesmo tempo da transformação voltada para a superação de todas as formas de discriminação, exclusão e destruição.

Para tanto, foram promovidas vivências e explorados conhecimentos relativos à história e ao cotidiano de jovens na cidade, criando condições para fazer germinar o referencial de identidade e o significado de preservação da vida e de todo o patrimônio que a cerca na perspectiva interdisciplinar. Integrando conteúdos da "Identidade Social e Sociocultural Brasileira" (PCNS, 1997), que, para a Bahia, denominamos "Bahia Plural", na sua abordagem foi somada a arte de fotografar, possibilitando a criatividade e registro do ambiente atual habitado pelos jovens.

Nas atividades teóricas educadores e jovens experimentavam momentos de ação e reflexão nas dinâmicas de grupo, em rodas de conversa, debates, simulações, sobre temas abordados e compartilhados através de leituras coletivas, músicas, exibição de slides, vídeos, filmes, 
mostra de fotografias, sobre a história da Bahia (desde o "descobrimento" do Brasil até os dias atuais) e outros relacionados à fotografia (noções da história da fotografia, a câmara fotográfica - composição e características, observação da luz). Conteúdos transversais como racismo, exclusão social, discriminação cultural, desigualdade regional, meio ambiente, observação, disciplina, reflexão, solidariedade, sensibilidade, responsabilidade, arte eram trabalhados ao longo das ações educativas. A complexidade do saber e do fazer pode, desta forma, ser aplicada ao longo de todo o aprendizado. Ao explorar o tema "Fundação da cidade do Salvador", por exemplo, foram tratados conteúdos sócio-econômicos a partir das presenças indígenas, africanas, européias na formação social brasileira, discutindo-se a exploração, degradação do meio ambiente, produção artística e cultural, paisagem urbana, relações de trabalho, escravidão, discriminação racial, etc. Sendo assim, foram explorados conteúdos sobre o "verdadeiro 'descobrimento' do Brasil", "a vida indígena, a presença portuguesa e suas consequências", "a chegada de Tomé de Souza e a construção da primeira capital do Brasil", "evolução urbana: o primeiro núcleo urbano e a atual cidade", "escravidão e racismo", "lutas pela liberdade: Alfaiates (1798) e Independência da Bahia (2 de julho de 1823)".

O jovem iniciou a aproximação com a fotografia conhecendo a história da fotografia no Brasil e na Bahia e as características da câmera fotográfica, através de projeções de imagens que exibiam aspectos do desenvolvimento urbano e de tipos humanos, fazendo o paralelo com a atualidade. Com a fotografia foram desenvolvidos exercícios de observação da luz, para a compreensão do princípio da reflexão e captação da luz, através da construção de uma "Câmera Escura", que denominamos "Caixa Mágica", onde eram refletidas imagens invertidas. Com a "Minha Primeira Câmera", criada a partir de uma moldura de slide, o educando tirou fotos imaginárias de seu cotidiano, o que provocou o aguçamento da observação, percepção e a compreensão de que a fotografia vem do fotógrafo e não da câmera.

A integração dos conteúdos de História com Fotografia culminou nas atividades práticas, quando grupos de jovens e educadores de história e fotografia saíam em passeios orientados e temáticos por lugares históricos 
da cidade, munidos de máquinas fotográficas e motivados pela curiosidade, onde eram exercitadas a observação, captação e exploração do ambiente, através de passeios à pé, de ônibus ou barco. Eram os espaços onde fotos eram produzidas com câmeras amadoras e se discutia conteúdos históricoculturais, sociais e ambientais do cotidiano, promovendo a relação entre presente e passado. Os jovens levavam consigo reflexões desenvolvidas nas atividades teóricas e a máquina fotográfica como recurso para a manifestação da observação e percepção. Neste sentido, o olhar do jovem sobre a cidade foi amplificado pela fotografia, através da qual aguçava-se a percepção nos seus diferentes ângulos. Cada atividade prática era precedida de uma ação educativa de avaliação de conteúdo e processo e de preparação para a próxima visita, quando se trabalhava pontos críticos e favoráveis sobre a última experiência e conteúdos sobre o local a ser visitado. $^{9}$

Identificamos pontos históricos relevantes que compuseram o percurso temático. O Centro Histórico foi onde os jovens iniciaram o exercício de fotografar o primeiro núcleo urbano construído pelos portugueses para sede do Governo Geral. A riqueza de informações absorvidas e transmitidas pelas fotografias puderam ser observadas pela captação de ângulos variados que abordaram temas diversificados integrantes da realidade local. Igrejas, artesanato, crianças, pobreza, velhos, arte sacra, praças, mar, feiras, etc. produziram o mosaico de interpretações e percepções sobre o ambiente.

Farol e Porto da Barra, com seus significados históricos, culturais, ambientais, arquitetônicos, por serem o território de chegada de Tomé de Souza, $1^{\circ}$ Governador da Bahia, que fundou a primeira capital do Brasil e possuir três fortalezas (Santo Antônio da Barra, Santa Maria e São Diogo), foram traduzidos pela paisagem natural da praia e do horizonte infinito, do pescador e das construções militares poeticamente integradas ao mar. Ali foi um dos lugares onde os jovens se apropriaram da técnica de fotografia e

\footnotetext{
${ }^{9}$ Foram visitados os seguintes pontos histórico-culturais: Centro Histórico de Salvador, Porto e Farol da Barra, Pirajá, Parque São Bartolomeu, Itapuã, Lagoa do Abaeté, Museu Wanderley Pinho-Candeias, Baía de Todos os Santos-Ilha de Maré, Cidade de Cachoeira, Ilha de Itaparica.
} 
do estímulo à observação e expressão. Os jovens realizavam fotos enquanto experimentavam vivências integradas ao conteúdo histórico-social, cultural, ambiental e artístico.

O Bairro de Pirajá, bairro periférico distante do circuito de visitações, foi destacado como ponto relevante para a construção de conhecimentos que convergiam simultaneamente com história, política, meio ambiente e práticas culturais. No âmbito histórico, foi palco das mais importantes batalhas para a expulsão dos portugueses na guerra pela independência da Bahia em 1823. Ali estão sepultados heróis anônimos que lutaram e morreram pelo ideal de liberdade. Possui o "Pantheon da Independência" onde está sepultado o "herói oficial" da guerra - General Labatut - e símbolos que marcam este fato histórico que a Bahia comemora todos os anos. Além da visão desta historicidade, o local foi, no tempo da escravidão, reduto de esconderijo de escravos fugidos que chegaram a formar quilombos. A Capela ali construída no século XVIII representa o grau de religiosidade presente na nossa cultura convivendo com terreiros de candomblé que cultuam a religiosidade africana.

Pirajá possui uma reserva ambiental da mata atlântica, tombada pela UNESCO. Ali resiste um patrimônio natural inigualável mais próximo ao perímetro urbano. O Parque São Bartolomeu, ali localizado, é um ambiente que contém elementos ecológicos e simbólicos significativos, onde a religiosidade africana é manifestada pelos cultos de respeito e veneração à mata, à água - existem cachoeiras como a de Oxum e Oxumaré - e ao local como um todo. O respeito a este espaço merece ser anunciado por diversas formas. A poluição das águas e a interferência ao meio através de construções desordenadas vêm gerando, se não estivermos atentos, a degradação não apenas ambiental, mas também cultural e social.

Considerando a importância do "2 de julho" para a Bahia, cuja data é comemorada a independência com desfile pelas ruas da cidade do Salvador, por onde o exército libertador passara em 1823, entendemos ser de grande relevância situar historicamente o jovem neste evento, a fim de estimular a sua participação. Foi fundamental transformar esta participação numa ação educativa, onde os jovens compartilhassem com maior consciência do grande espetáculo popular que representa o "2 de Julho" para a Bahia. 0 
tema que conduziu as comemorações em 1998 foi "Conjuração Baiana" ou "Conspiração dos Alfaiates" ou "Revolta dos Búzios" que completava 200 anos de uma luta popular que defendeu, entre outras idéias, a República e o fim da escravidão. O trabalho realizado com os jovens para este evento culminou na realização de uma "caminhada perfomática" criada e produzida pelo então Núcleo de Teatro do Liceu.

Um roteiro que não se acaba. Experiências que se transformaram em conhecimentos. Fotografias que produziram impactos de leituras e qualidade estética. Uma metodologia que gerou novos projetos educativosculturais realizados em Itaparica e Região Sisaleira, envolvendo outros jovens e novos aprendizados.

A participação dos jovens em todo o processo educativo aconteceu de forma ativa, autônoma, manifestada pelas fotografias realizadas e depois analisadas uma a uma na atividade conclusiva. Era o momento em que recebiam as fotos reveladas e copiadas num clima de emoção e euforia. Num exercício de observação, avaliação, exploração e valorização do trabalho fotográfico produzido, as fotos eram selecionadas para a montagem de cartazes, levando-se em conta a coerência ao conteúdo e à lógica visual interna ao trabalho. Produziam-se textos sobre a vivência no projeto e as imagens e eram realizadas leituras individuais e coletivas em torno dos cartazes. O resultado final era a montagem de uma exposição. Foram montadas exposições com as fotografias e textos síntese sobre o aprendizado e as caixas mágicas confeccionadas pelos jovens que percorreram os salões de exposição do Liceu de Artes e Ofícios, o Shopping Barra, o Salão Negro do Congresso Nacional, por ocasião das comemorações dos 450 anos da Cidade do Salvador (1999), entre outros espaços culturais da Cidade.

\section{Algumas Reflexões e Impactos da Experiência}

O diálogo entre as práticas e os princípios teórico-metodológicos adotados neste Projeto provocou algumas reflexões que podem contribuir para o alargamento de outras experiências interdisciplinares que associem, 
no âmbito da educação patrimonial, o ensino da história com a fotografia. Ou ainda, a associação entre educação, história, arte e antropologia visual, vetores para uma abordagem patrimonial em educação, estabelecida durante a experiência, cujo resultado foi a criação de uma nova metodologia de ensino-aprendizagem, a qual poderá ser replicada e aperfeiçoada. Contudo, merece aprofundamentos teórico-conceituais em torno de temas da antropologia visual, imagem e cognição, história e imagem, fontes visuais ${ }^{i}$, bem como sobre métodos e abordagens para uma educação popular de combate ao analfabetismo e aplicação de uma pedagogia libertadora, não opressora, que considere os diversos saberes e experiências de pessoas que têm o direito de potencializar suas existências no mundo como cidadãos ativos, participativos, criativos e críticos.

Neste sentido, a estratégia de utilização de recursos visuais durante as atividades teóricas foi relevante, uma vez que os conteúdos históricos discutidos estiveram referenciados a documentos visuais, sejam fotografias, desenhos, pinturas e filmes. Não somente analisando o objeto visual em si, buscou-se discutir seus conteúdos, potencializando as informações presentes nas imagens, produzindo leituras de um "texto" elaborado para comunicar e apropriado pelos "leitores" de forma que desse sentido e fosse compartilhado com o coletivo de educandos e educadores. Os recursos visuais puderam ser interpretados não somente na sua dimensão histórica por exemplo uma imagem de Rugendas do século XIX retratando o desembarque de escravos em um porto - mas os significados social, político, cultural e econômico ali representados. Os elementos que compõem o "quadro" do tráfico de escravos no Brasil e seus desdobramentos para além da imagem, para além do tempo. Um documento visual que registra a sociedade observada e interpretada pelo observador e pelo produtor, estabelecendo uma interação com o significado do registro. 10

\footnotetext{
${ }^{10}$ Sobre as relações entre história, educação, imagem e estética ver SALIBA, Elias Thomé. $A$ produção do conhecimento histórico e suas relações com a narrativa fílmica. São Paulo, FDE, 1992; DUARTE Jr., João Francisco. Fundamentos estéticos da educação. Campinas, Papirus, 1988; ALMEIDA, Milton José de. História em imagens e sons na moderna história oral. São Paulo, FDE, 1992.
} 
Através de leituras e debates elaborados e compartilhadas sobre as imagens apresentadas, questões polêmicas sobre património histórico foram levantadas naquilo que significa preservar, conservar, proteger. Os jovens se identificavam com a idéia de preservação de uma cultura de discriminações e preconceitos construída em torno do negro na contemporaneidade a partir da diáspora? Ou a idéia de patrimônio estaria associada à transformação cultural, social, política sobre as práticas do passado escravista e as de um presente cidadão? Dos elementos vinculados à presença negra na história do Brasil e da Bahia em particular, quais são identificados como patrimônio a ser preservado, protegido, e quais deverão ser superados na sociedade contemporânea? Que história pode ser escrita pelas letras da cidadania?

Debates sobre a experiência negra na história brasileira, nas suas lutas de resistência, nas negociações, nas elaborações e reelaborações sobre o lugar de pertença dos negros na sociedade atual, foram recorrentes. Afinal, a maioria dos educandos envolvidos era negra, pobre e com experiências de vida bastante difíceis. Podemos afirmar que os conteúdos historiográficos sobre as temáticas abordadas foram plenamente compreendidos, assimilados, questionados e refletidos à luz das experiências e leituras de cada um. A partir das "provocações temáticas", muitos jovens buscaram aprofundar conteúdos e análises nos livros, na internet, nos periódicos, pesquisando e retornando com mais propriedade sobre os temas de interesse. Ou seja, o estímulo à pesquisa foi um dos resultados importantes deste projeto. Tais pesquisas foram apresentadas espontaneamente e outras realizadas para fins escolares. Outros impactos foram identificados com relação ao desejo de muitos educandos se tornarem historiadores.

Tomando como exemplo de análise a foto abaixo (Foto 2 ) realizada pelos educandos, podemos refletir sobre algumas dimensões trabalhadas na presente experiência, as quais respondem positivamente aos propósitos iniciais, além de provocarem novas discussões sobre a relação entre história e documento visual, neste caso, documento produzido ao longo das práticas educativas vivenciadas e aplicadas pelos protagonistas da ação educadores e educandos. 


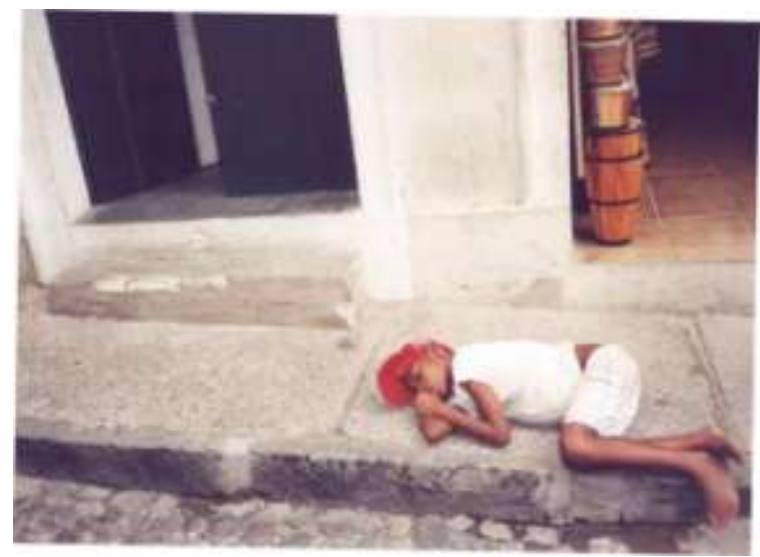

Foto 2 - Criança no Pelourinho - Salvador/Bahia, $1998^{11}$

"Observamos o nosso passado de forma ampla e descobrimos novas formas de olhar o mundo".

Lívia Santos; Nayara Silva; Rutemberg Trindade (16 anos)

Os aprendizados reunidos nos conteúdos específicos de história e fotografia resultaram em sínteses interessantes que envolvem conteúdo, interpretação, percepção sobre a realidade, criatividade associada à produção artística, técnica e à reportagem-denúncia. Na fotografia acima, a rua de pedras "cabeça de nego", a calçada, a porta de uma casa secular, instrumentos musicais de percussão de matriz africana, como o timbau, compõem a cena escolhida pelo observador que reuniu em um só instante os elementos "patrimoniais" da cultura da cidade. Contudo, no primeiro plano, a criança negra, descalça, dormindo à beira da calçada, protagoniza e denuncia o momento, o que sugere a discussão sobre a problemática da criança abandonada, da pobreza associada ao negro, da droga vinculada a dezenas de crianças que vivem no Centro Histórico de Salvador e a inexistência de políticas públicas de enfrentamento de tais situações. Sociedade, cultura, história, política, economia estão presentes neste documento histórico produzido pelo jovem educando que comunicou a sua compreensão sobre a historicidade daquela criança no ambiente secular e contemporâneo. Discutindo escravidão, preservação do patrimônio arquitetônico e imaterial da musicalidade negra, representada pelos

${ }^{11}$ Foto premiada no $3^{\circ}$. lugar do Concurso promovido pelo Movimento Internacional para uma Nova Museologia (MINOM) sobre "Patrimônio, Juventude e Desenvolvimento: os desafios do século XXI" em 1999. 
instrumentos vinculados ao candomblé, à capoeira, ao samba, a sociedade do pós-abolição, o jovem reuniu elementos que sintetizaram aprendizados, os quais foram plenamente captados, traduzidos e fixados na foto com produção de sentido.

A fotografia, nessa perspectiva, provocou o poder de reflexão e criatividade dos jovens, propiciando o reconhecimento de que são capazes de produzir fontes de informações no que há de tangível e intangível. Fotografar o aprendizado histórico criou a possibilidade de inserção mais direta do jovem no processo de conhecimento, pemitindo que as suas interpretações fossem expressas de forma visual e integradas, potencializando a dimensão cognitiva da imagem no interior da vida social. Por reconhecermos que a nossa cultura está associada à visualidade, consideramos, a partir dos resultados apresentados, a natureza discursiva presente nesta importante fonte visual ${ }^{12}$.

Educação e arte favoreceram a integração da criatividade ao desenvolvimento do conhecimento, do senso crítico e estético. Foi um passo significativo para o efetivo exercício pedagógico, especialmente por considerarmos como objetivos da educação o estímulo às potencialidades do ser humano e a sua preparação para o exercício pleno da cidadania, no qual está incluído, entre outros aspectos, o acesso ao mundo do trabalho. (COSTA, 1998). Mundo este que se "desmaterializa" e exige das novas gerações a capacidade de percepção do todo, de expressar-se, de contribuir criativamente para o enfrentamento de desafios no processo contínuo de elaboração, proposição e realização dos projetos de vida de cada um. Educação, arte e trabalho, neste sentido, convertem-se "num poderoso catalizador do desenvolvimento humano", essencial para potencializar o exercício pleno da cidadania. O desenvolvimento das habilidades artísticas, pode ser transferida para o trabalho e para a vida em geral, promover a comunicação eficaz e propiciar uma abordagem criativa à solução de

\footnotetext{
12 Ver MENESES, 2003, a discussão sobre a importância dos historiadores se interessarem nas fontes visuais (iconografia, iconologia) para um tratamento mais abrangente da visualidade como uma dimensão importante da vida social e dos processos sociais e plataforma estratégica de elevado interesse cognitivo.
} 
problemas, considerando ser a arte parte da formação do ser humano. (KLINTOWITZ, 1998)

A prática da observação e percepção foi aplicada no ato de fotografar, por considerar que a fotografia não se faz apenas com a máquina e a técnica, mas com a percepção, o conhecimento, a sensibilidade, a reflexão e a crítica. Não somente foram reproduzidos e documentados o visível dos elementos arquitetônicos ou naturais que compõem o mosaico patrimonial da cidade do Salvador. Nas leituras textuais e visuais produzidas pelos jovens estão focalizadas as dinâmicas sociais, culturais, artísticas, presentificadas nos sujeitos que habitam e vivem o cotidiano nos espaços de trabalho, de lazer, turísticos, religiosos, naturais. A qualidade estética associada aos conteúdos histórico-culturais, agrega valor à elaboração cuidadosa realizada na captação do tangível e intangível, oferecendo visualidade às imagens reconstruídas pelo olhar ampliado de um instante, conforme Meneses, ao discutir sobre o sentido da expressão "História Visual" no âmbito da utilização de fontes documentais para os estudos históricos e a sua relação com o objetivo da História ser o exame da dimensão visual da sociedade:

\footnotetext{
"Visual" se refere, nessas condições, à sociedade e não às fontes para seu conhecimento - embora seja óbvio que aí se impõe a necessidade de incluir e mesmo eventualmente privilegiar fontes de caráter visual. Mas são os problemas visuais que terão de justificar o adjetivo aposto a "História". (MENESES, 2003, p. 28)
}

As atividades de fotografia favoreceram à produção estética, desde o processo da construção da "caixa mágica", quando evidenciou-se uma intervenção plástica nas formas e cores das colagens e pinturas realizadas sobre a caixa de papelão, até os resultados das fotos, com a beleza das composições, enquadramentos, cores e riqueza de elementos, indicando a presença de estilo pelos enquadramentos e escolha de tema recorrente. Ficou constatado que a fotografia provoca uma nova maneira de "alfabetizar" jovens através de uma outra linguagem - a visual. A linguagem fotográfica remete ao raciocínio concreto, diferentemente da verbal que fragmenta a realidade de forma abstrata. A introdução da 
fotografia como linguagem expressiva ofereceu iguais oportunidades a todos os jovens. Aqueles com deficiência na linguagem escrita expressaram competência e desenvoltura. A igualdade de condições no grupo teve efeito imediato no comportamento, promovendo uma efetiva integração de todos os participantes dos diferentes grupos.

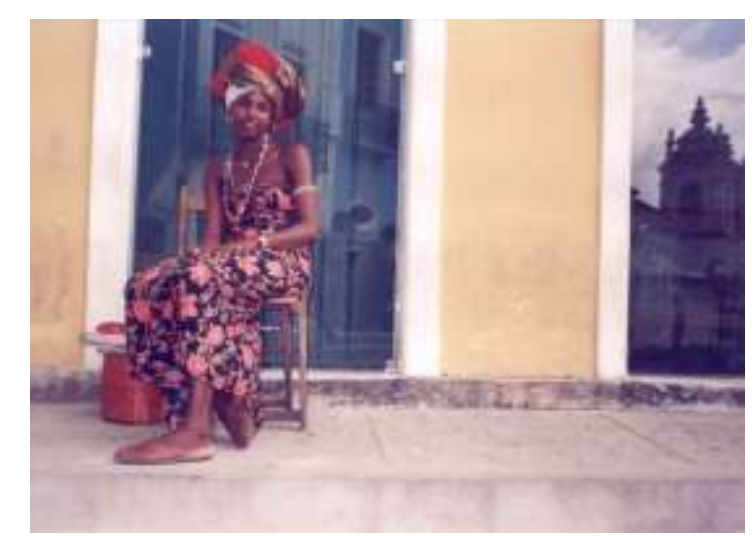

Foto 3 - Baiana no Pelourinho com adereços tradicionais - Salvador/Bahia, $1998^{13}$

\begin{abstract}
"Fotografar é registrar na consciência aquilo que você viu e verá para sempre; é guardar uma mensagem em forma de imagens, beleza, realidade e experiência".

Nicole Silva(17); Alice Pereira(17);Marcelo Pereira(15)
\end{abstract}

Outro aspecto merecedor de destaque está na prática educativa nas ruas de Salvador. O espaço aberto, repleto de conteúdos e paisagens transformou-se em importante "sala de aula". As fronteiras de paredes e instituições foram ultrapassadas e ricamente reconstruídas nas rotinas, no cotidiano das ruas. Os educandos tiveram a oportunidade de por em prática o conjunto de conhecimentos sobre história da Bahia e fotografia discutido nas atividades teóricas. Assim, através do olhar reflexivo e criativo, ricos momentos foram vivenciados com uma câmera fotográfica nas mãos. Foram nas ruas que os educandos desenvolveram competências e capacidades até então adormecidas ou inexistentes: a história presente em cada pedaço de chão, em cada pedra fincada; o conhecimento de aspectos variados da cidade em que habitam; a importância da preservação do

${ }^{13}$ Foto premiada em $1^{\circ}$. lugar do Concurso promovido pelo Movimento Internacional para uma Nova Museologia (MINOM) sobre "Patrimônio, Juventude e Desenvolvimento: os desafios do século XXI" em 1999. 
patrimônio artístico e cultural de um povo; assim como sobre a fotografia, sua importância e a melhor forma de fotografar.

Conhecer os diversos pontos da cidade estimulou jovens a se interessarem pela sua vida na cidade, de forma a estabelecer o diálogo entre o conhecimento teórico e o empírico, sobre o que outras dimensões puderam ser reveladas e internalizadas em torno de valores sócio-culturais, a exemplo da valorização do conhecimento histórico para a vida individual e coletiva, sensibilização para a proteção do patrimônio histórico-cultural em seu sentido largo, valorização das origens étnicas de cada um e de todos, respeito e motivação pela preservação do meio ambiente, na simplicidade de "poder conhecer o lugar onde moramos", conforme a educadora Suzana Esteves. Assim, todos foram sensibilizados e estimulados a observar e perceber que o resgate da sua memória está incluído no exercício da cidadania. Afinal, só amamos o que conhecemos; só preservamos o que amamos; só defendemos aquilo com que nos identificamos.

A transformação na visão dos adolescentes sobre o conhecimento histórico, sensibilizados sobre o seu valor na vida de cada um e na vida coletiva, não somente foi observada durante as atividades, mas constatada através das avaliações realizadas em processo. Como espaços de reflexão, não apenas para a verificação dos aprendizados, fortaleceram e ajudaram a corrigir os rumos da experiência tanto para educadores como educandos. Em rodas de conversa, educadores e educandos refletiam sobre o conjunto das atividades associando à auto-avaliação, no que havia de significativo para cada um e para o grupo. A demonstração, seja pela oralidade ou escrita, do grau de satisfação e importância das experiências objetivas e subjetivas para a vida intelectual, profissional e pessoal dos envolvidos, foi, sem dúvida, o coroamento e reforço para a continuidade e aperfeiçoamento de uma metodologia que aponta para a abertura de possibilidades para o desenvolvimento da cognição, da escrita, da oralidade, da percepção estética, da reflexão crítica sobre a realidade social, política, cultural, ambiental do país e da cidade, bem como para o estabelecimento de relações interpessoais que proporcionaram encontros e entendimentos sobre as diferenças e os diferentes, criando-se um ambiente de amizade, integração, solidariedade, sensibilidade, respeito, superando-se momentos 
de conflito surgidos, em grande parte, pela disputa por uma câmera fotográfica ou durante debates sobre temas como pobreza, drogas, política, sexualidade. ${ }^{14}$

Outro aspecto a ser destacado sobre os impactos do Projeto foi 0 fortalecimento para os estudos escolares formais. Os jovens revelaram a melhoria no desempenho escolar nas diversas disciplinas, especialmente em História. São elementos que vêm fortalecer a grande discussão sobre a qualidade no ensino, especialmente nas escolas públicas. As metodologias ultrapassadas, a falta de atualização e qualificação na formação dos docentes, entre outros quesitos, foram assuntos revelados ao longo das atividades e discutidos com os jovens.

Na perspectiva da pluralidade cultural na Bahia, significou ainda abrir mais um canal de conhecimento que provocou a ampliação de visão de mundo e de sociedade, entendendo que "a realidade em que vivemos é apenas parte de um mundo complexo, fascinante e desafiador, na qual o elemento universal subjacente e definidor das relações intersociais e interpessoais deve ser a Ética" (PCNS, 1997, p. 21). Coexistir com a ampla diversidade étnica e religiosa em solo baiano, por exemplo, é reconhecer a multiplicidade de alternativas. Do plural que há nas manifestações externas, sociais, culturais, chega-se à constatação do potencialmente plural que está em cada um, considerando que "o princípio de liberdade se afirma nas possibilidades múltiplas de cada um, na polissemia subjetiva que permite escolhas e novos encontros." (PCNS, 1997, p. 21)

No projeto Conhecendo a Cidade, Descobrindo o Olhar, o objeto de conhecimento foi estendido para além do patrimônio cultural material ou imaterial, dos conteúdos históricos, artísticos, culturais, técnicos, ao integrar diversas dimensões das experiências humanas, sejam cognitivas, sociais, estéticas, afetivas, vinculando-as ao propósito de mobilizar os jovens para conquistar a sociedade na condição de cidadãos com rostos, idéias, desejos, incluídos para protagonizar as cenas que se sucedem na vida social e individual daqueles que vislumbram uma sociedade justa,

14 Sobre avaliação escolar ver DEMO, P. Avaliação qualitativa, São Paulo, Cortez Editora, 1987; VASCONCELOS, C. dos S. Avaliação: concepção dialética-libertadora do processo de avaliação escolar, 9 ed. São Paulo, Libertad - Centro de Formação e Assessoria Pedagógica, 1998. 
equânime, solidária, tomando o eixo "património" na largueza do seu conceito. Uma metodologia de ensino foi desbravada com a curiosidade própria do pesquisador que pretende aplicar o que a teoria vem discutindo sobre tantos conceitos relacionados à educação, memória, património, história e imagem, história e visualidade, antropologia visual, entre tantas outras dimensões conceituais ainda a serem exploradas. Acreditamos que, nesta experiência em particular, pudemos colocar na prática conceitos analisados e discutidos pelos teóricos das áreas da educação, história, antropologia, sociologia, das artes visuais, do património, e ao mesmo tempo proporcionar novas revelações que poderão inspirar e sensibilizar educadores para a implementação de experiências pedagógicas renovadas, críticas, comprometidas com o salto de qualidade que ainda precisamos perseguir na educação brasileira.

\section{Referências}

CARNEIRO, N. de P. Da memória à história. Disponível em http://www.webartigos.com/articles/5296/1/da-memoria-ahistoria/pagina1.html. Acesso em 09/abril/2008.

CASCO, A. C. A. Sociedade e educação patrimonial. Revista Eletrônica do Instituto do Patrimônio Histórico e Artístico Nacional. Educação Patrimonial: n03. Jan/fev. 2006. (www.iphan.gov.br). Disponível em http://www.revista.iphan.gov.br/materia.php?id=131

CHAUÍ, M. Convite à filosofia. 13 ed. São Paulo: Ática. 2005, p. 138.

COSTA, A. C. G. da. Educação Artística, Trabalho e Vida. Modus Faciendi, 1998.

FERNANDES, J. R. O. Educação Patrimonial e Cidadania: uma proposta alternativa para o Ensino de História. Revista Brasileira de História. São Paulo, v. 13, n. 25/26, p. 265-276, set./ago. 1992/1993.

GUIMARÃES, E.; MIRANDA, M. P. de S. A Educação patrimonial como instrumento de preservação. Revista por dentro da história, Ano 1, número 2, agosto 2009. Contagem-Minas Gerais. Disponível em http://novo.contagem.mg.gov.br/arquivos/publicacoes/pordentrodahistoria 02/pdf. 
KLINTOWITZ, J. Arte Pública e Identidade. Inovação Empresarial, jan/1998.

LE GOFF, J. História e Memória. 4. Ed. Campinas, S.P.: Ed. Da Unicamp, 1996.

MARIUZZO, P. A construção histórica do patrimônio público in Revista Consciência No. 52 - Março 2004, disponível em http:// www.comciencia.br/reportagens/memoria/02.shtml. Acessado em $10 / 6 / 2004$.

MENESES, U. T. B. A crise da Memória, história e documento In SILVA, Z. L. da (org.). Arquivos, patrimônio e memória: trajetórias e perspectivas. São Paulo: UNESP; FAPESP, 1999, pp. 11-29.

. Fontes visuais, cultura visual, história visual: balanço provisório, propostas cautelares. Revista Brasileira de História. São Paulo, v. 23, n. 45, Jul. 2003.

ORIÁ, R. Memória e Ensino de História in BITTENCOURT, Circe (Org.). $O$ Saber Histórico na Sala de Aula. 5 ed. São Paulo: Contexto. 2001

BRASIL, Parâmetros Curriculares Nacionais (PCNs), Temas Transversais Pluralidade Cultural e Sociocultura brasileira. Secretaria da Educação Fundamental. Brasília: MEC, 1997. 